\title{
Growth Promotion, Nutrition Levels, and Antioxidant Activity in Peucedanum japonicum Thunb. under Various Plant Extracts
}

\author{
Se Ji Jang, Hyun Hwa Park and Yong In Kuk* \\ Department of Oriental Medicine Resources, Sunchon National University, Suncheon 57922, Korea; \\ sjsj@sunchon.ac.kr (S.J.J.); camellia9720@s.scnu.ac.kr (H.H.P.) \\ * Correspondence: yikuk@sunchon.ac.kr
}

Received: 31 August 2020; Accepted: 28 September 2020; Published: 1 October 2020

\begin{abstract}
This study examined the growth promotion effects of selected water extracts on Peucedanum japonicum. As secondary considerations, the mineral nutrition levels were measured in both the extracts and the test plant. In addition, the levels of chlorophyll and the photosynthetic efficiency in the test plant were analyzed after the treatment of selected plant extracts. Finally, the total phenol, flavonoid contents, and DPPH (2,2'-diphenyl-1-picrylhydrazyl) radical scavenging activity in Peucedanum japonicum leaves were determined after the extract treatments. The shoot fresh weight of Peucedanum japonicum increased in response to all the extracts used, and in some cases increased at rates of $16-49 \%$ after extract treatments. Compared to the control, the photosynthetic efficiency and chlorophyll content of the Peucedanum japonicum plants did not vary significantly. In measuring the macro and microelements in the extracts, those with the highest levels were not necessarily the most effective growth promotors of Peucedanum japonicum plants. However, nutrition levels increased significantly in Peucedanum japonicum leaves after extract treatments. The total phenol contents in the Peucedanum japonicum leaves increased significantly when treated with the soybean stem extracts at 3\%, Chinese chive extract at $0.5-3 \%$, onion extract at $0.5 \%$, or tomato extract at $3 \%$. The total flavonoid contents in the Peucedanum japonicum leaves treated with the soybean leaf extracts at 0.5 to $3 \%$ increased by $23-36 \%$ compared to the control, but there were no differences with other extracts. Thus, the plant extracts tested in this study showed improved growth promotion, mineral contents, total phenol, total flavonoid contents, and DPPH radical scavenging activity.
\end{abstract}

Keywords: antioxidant activity; growth promotion; nutrition; Peucedanum japonicum; photosynthesis; plant extract

\section{Introduction}

Organic agricultural practices are becoming more popular because of increased consumer interest and the demand for safer agricultural products [1]. As the use of synthetic chemicals to control diseases, insects, and weeds is prohibited in organic agriculture, treatments made from natural ingredients that are safe to humans and the environment must be used instead [2]. In addition, organic agriculture seeks to promote crop growth through systems that use crop rotation, allow for fallow fields, and use green manure cultivation rather than chemical fertilizers for crop cultivation. On the other hand, these methods can cause nutrient deficiency during several crop growth periods [1,3]. The challenges and shortcomings of these methods are apparent in organically cultivated crops with longer cultivation periods, such as Peucedanum japonicum.

Peucedanum japonicum Thunb is a perennial herb belonging to the Apiaceae family commonly used as a medicinal plant. In oriental medicine, its roots are used to treat ailments ranging from headaches 
to hypertension [4]. In recent years, however, the young leaves and stems of this plant have become a common ingredient in salads. Owing to its increasing popularity, this study examined this plant to determine how its growth levels might be improved with the application of liquid fertilizers made using extracts from organic materials.

Liquid fertilizers are used by organic farmers to supplement the nutrient needs of their crops. They are often made using plant by-products, such as rice bran and soybean oil cake, or waste products, such as onion and tomato [3,5]. Plant by-products contain many minerals and bioactive substances that can improve both the yield and quality of crops [6,7]. Plant by-products are also abundant. Onions and tomatoes, in particular, produce tremendous amounts of waste during cultivation, after harvest, and during storage, which can be used to produce liquid fertilizers.

The effectiveness of liquid fertilizers varies considerably depending on which extraction methods and raw materials are used. For example, tomato and red pepper crops experience higher rates of growth promotion when treated with water extracts made from tomato, onion, and red pepper leaves than when they were treated with fermentation extracts [5,8]. In addition, previous studies examined 31 different organic materials and produced 82 different extracts using a range of extraction methods. Of those extracts, the effectiveness varied widely, but the extracts using soybean leaves and stems, Chinese chive, onion, and tomato produced some of the most effective growth promoters [9]. Therefore, this study applied the aforementioned liquid fertilizers to Peucedanum japonicum Thunb.

The mechanisms through which plant extracts improve plant growth have not been researched thoroughly, nor are they completely understood. Khan et al. [10] reported that some seaweed extract applications stimulate root growth, and increase mineral uptake and photosynthetic capacity, which ultimately leads to growth promotion. Several other studies reported that the chlorophyll content was increased following seaweed extracts [11-13]. Therefore, this study examined both the chlorophyll and mineral content as well as the plant photosynthetic efficiency because these have been linked to growth promotion in previous studies.

Secondary metabolites, such as phenolic acids and flavonoids, play a large part in determining a plant's nutritional benefits as well as their ability to resist disease. Normally, phenolic acids and flavonoids are produced constitutively in plants during normal growth and development [14]. On the other hand, the synthesis of these compounds can also be induced by introducing a range of biotic and abiotic stresses, such as UV-B radiation, chilling, wounding, salt, and drought [15]. Lettuce plants exposed to UV-B had an increased concentration of polyphenols and flavonoids [16]. After treatments with an Ascophyllum nodosum extract $(1.0 \mathrm{~g} / \mathrm{L})$, total phenolic and flavonoid content of treated spinach leaves increased significantly [17]. Nevertheless, there are no studies on how phenolic acids and flavonoids might be increased in Peucedanum japonicum after the application of soybean leaves and stems, Chinese chive, onion, and tomato water extracts.

Therefore, this study was conducted with primary considerations. The growth promotion effects of selected water extracts on Peucedanum japonicum were evaluated. The mineral nutrition levels in both extracts and the test plant were then measured. The levels of chlorophyll and photosynthetic efficiency in the test plant were also measured after the treatments with the selected plant extracts. Finally, the total phenol and flavonoid contents, and DPPH radical scavenging activity in Peucedanum japonicum leaves were determined after various extract treatments.

\section{Materials and Methods}

\subsection{Plant Materials}

Chinese chive (Allium tuberosum; cv. Jaeraejong), onion (Allium cepa L. cv. Sinseonhwang), and tomato (Lycopersicon esculentum; cv. Berrykings) powder were purchased from Chonnam Hanyaknonghyup Corporation (Hwansun, Korea). Soybean leaves and stems were provided from the Jeollanamdo Agricultural Research and Extension Service after harvest in 2018 and dried in a drying 
oven at $40{ }^{\circ} \mathrm{C}$ for five days. They were ground to pass a 2-mm screen using a coffee grinder (Proctor Silex E160B, Southern Pines, NC, USA). All materials were organically cultivated and harvested.

\subsection{Extracts and Growth Promotion}

For the water extracts, $50 \mathrm{~g}$ of ground materials (Chinese chive, soybean leaves, soybean stems, onion, and tomato) was mixed with $1000 \mathrm{~mL}$ of distilled water for $24 \mathrm{~h}$ in a shaking incubator. The resulting mixture was filtered through two layers of miracloth and filtered again through Whatman (No. 1) filter paper. Subsequently, a vacuum dryer (Hanbaek Scientific Co., Siheung, Korea) was used to reduce the supernatants to a $50 \%$ concentration.

The seeds of Peucedanum japonicum (cv. Jaeraejong) used in this study were purchased from Dong Won Nong San Seed Co., Ltd. (Seoul, Korea). They were sown into a 72-cell tray filled with commercial soil ('Tobaek' Sunghwa Co., Ltd., Bosung, Korea). Twenty days after sowing, the germinated seedlings were transplanted into vinyl pots ( $\varphi 180 \mathrm{~mm}$ ). Various extracts at $0.5 \%, 1 \%$, and $3 \%$ concentrations were used to drench the soil at 50 days after sowing. The application volume was $2000 \mathrm{~L} / \mathrm{ha}$. The plant height and fresh shoot weight were measured 14 days after the treatments were applied. The greenhouse conditions were maintained at $30 / 20 \pm 2{ }^{\circ} \mathrm{C}$ day/night temperatures with a $12 \mathrm{~h}$ photoperiod, $65 \%$ relative humidity, and light intensity $\left(500 \mu \mathrm{mol} \mathrm{m}^{-2} \mathrm{~s}^{-1}\right)$.

\subsection{EC and $p H$ in Extracts}

The extract stability was confirmed by measuring the extracts' EC and $\mathrm{pH}$ at monthly intervals. The EC of all the extracts was measured using a compact conductivity meter (LAQUtwin-EC-22, Horiba, Japan), and the $\mathrm{pH}$ was measured using a compact $\mathrm{pH}$ meter (LAQUtwin-pH-22, Horiba, Japan).

\subsection{Photosynthetic Efficacy and Total Chlorophyll Reading (SPAD)}

Chlorophyll fluorescence measurements for the photosynthetic performance were taken using a handheld fluorometer-FluorPen FP100 (Photon Systems Instruments, Drásov, Czech Republic). Fifty days after sowing, the fifth leaves on each plant were selected for measurement. Before the measurements $\left(\mathrm{F}_{\mathrm{v}} / \mathrm{F}_{\mathrm{m}}\right)$, the leaves were dark-adapted for $15 \mathrm{~min}$ to open all the antennae pigments.

The relative chlorophyll concentration was determined using a non-destructive method. The SPAD value of the leaf was determined using a chlorophyll meter SPAD-502, according to the Soil Plant Analysis Department Section, Monolta Camera Co., Osaka, Japan. Photosynthetic efficacy and SPAD values were measured at seven and 14 days after the treatment. In measuring both the chlorophyll fluorescence and relative chlorophyll concentration, measurements were taken from two different areas of the fifth leaf of each plant.

\subsection{Levels of Mineral Nutrition in Extracts and Treated Leaves}

An analysis of mineral nutrition was determined in both the extracts themselves and leaves of the plants that received the extract treatments in accordance with the Soil and Plant Analysis Method published by the Rural Development Administration [18]. The mineral nutrition was measured at 14 days after treatment. The nitrogen content was analyzed using an automatic nitrogen analyzer (Buchi Co., Flawil, Switzerland). The effective phosphoric acid content was analyzed using an absorbance photometer (Cintra 40, GBC Scientific Equipment, Ltd., Mt. Eliza, Vic, Australia), and the levels of $\mathrm{K}, \mathrm{Ca}, \mathrm{Ma}$, and microelements were analyzed by inductively coupled plasma-atomic emission spectroscopy (ICP-AES, Integra XL Dual, Scientific Equipment, Ltd., Dandenong, Vic, Australia) $[5,8]$.

\subsection{Phenol and Flavonoid Contents and DPPH Radical Scavenging Activity}

The total phenol and flavonoid contents and the DPPH radical scavenging activity were measured in both the control leaves and those that had received the extract treatments at $0.5,1$, and $3 \%$ concentrations. To determine the total concentrations of phenol and flavonoid as well as the DPPH 
radical scavenging activity, $0.2 \mathrm{~g}$ of both the treated and control leaves were ground by hand using a mortar and pestle after being mixed with $5 \mathrm{~mL}$ of $100 \%$ methanol. After this initial procedure, the supernatants were used for further analysis $[19,20]$.

In measuring the phenol content, $1 \mathrm{~mL}$ of the supernatant was taken and mixed with $3 \mathrm{~mL}$ distilled water and $1 \mathrm{~mL}$ Folin-Denis' reagent and shaken for $5 \mathrm{~min}$. The mixed solution was then left for one hour at room temperature and measured calorimetrically using a UV spectrophotometer at $640 \mathrm{~nm}$ (UV1601; Shimadzu Co., Kyoto, Japan) [19,20].

In measuring the flavonoid content, $0.5 \mathrm{~mL}$ of the supernatant was mixed with $1.5 \mathrm{~mL}$ ethanol (95\%), $10 \% \mathrm{AlCl}_{3}, 1 \mathrm{M}$ potassium acetate, and $2.8 \mathrm{~mL}$ distilled water. The mixed solution was then left for $40 \mathrm{~min}$ at room temperature and measured calorimetrically using a UV spectrophotometer at 415 nm (UV-1601; Shimadzu Co., Kyoto, Japan) [19,20].

In measuring the DPPH radical scavenging activity, $0.1 \mathrm{~mL}$ of supernatant, $0.5 \mathrm{~mL}$ of $0.1 \mathrm{M}$ acetate buffer solution (pH 5.5), $0.25 \mathrm{~mL}$ of $0.5 \mathrm{mM}$ DPPH (2,2-diphenyl-1-picrylhydarzyl), and $0.4 \mathrm{~mL}$ ethanol were mixed for $30 \mathrm{~min}$ at room temperature. The mixed solution was then determined calorimetrically using a UV spectrophotometer at $517 \mathrm{~nm}$ (UV-1601; Shimadzu Co., Kyoto, Japan) to measure the scavenging activity $[19,20]$.

\subsection{Statistical Analysis}

The data were analyzed using the analysis of variance (ANOVA) procedure in the Statistical Analysis Systems [21] software. The means were separated using a Duncan's multiple range test $(p=0.05)$.

\section{Results and Discussion}

\subsection{Extract Stability}

Through previous studies using 31 different organic materials and various extraction methods, highly effective growth promotors of crops could be identified $[9,19]$. Of all the extracts studied, those made using soybean leaves and stems, and Chinese chive extracts produced the most effective growth promotors of lettuce and kale crops. In contrast, the onion and tomato extracts were the most effective red pepper and tomato crop growth promotors [8,9]. Thus, this study used the water extracts of soybean leaves, soybean stems, Chinese chive, tomato, and onion because they had been the most effective growth-promoting extracts from all previous studies.

Before measuring growth promotion effectiveness in this study, the extract stability was first determined (Figure 1). All extracts tested had neutral $\mathrm{pH}$ levels in the range of 6.8-7.1 when measured at zero days after extraction. The $\mathrm{pH}$ of all extracts was relatively constant from 0 to 30 days after extraction. Although the extraction EC values varied, none of the extract EC values were high, ranging from just 11.9 to $34.1 \mathrm{mS} \cdot \mathrm{cm}^{-1}$ from 0 to 30 days after extraction. Therefore, all extracts are suitable for use in organic agriculture. In previous studies [8,20], however, the range of $\mathrm{pH}(5.2-5.8)$ and EC $\left(2.0-4.3 \mathrm{mS} \cdot \mathrm{cm}^{-1}\right)$ of the extracts were different, despite using the same materials. This discrepancy was attributed to variations in the extraction methods, manufacturing process, and amount of material. 


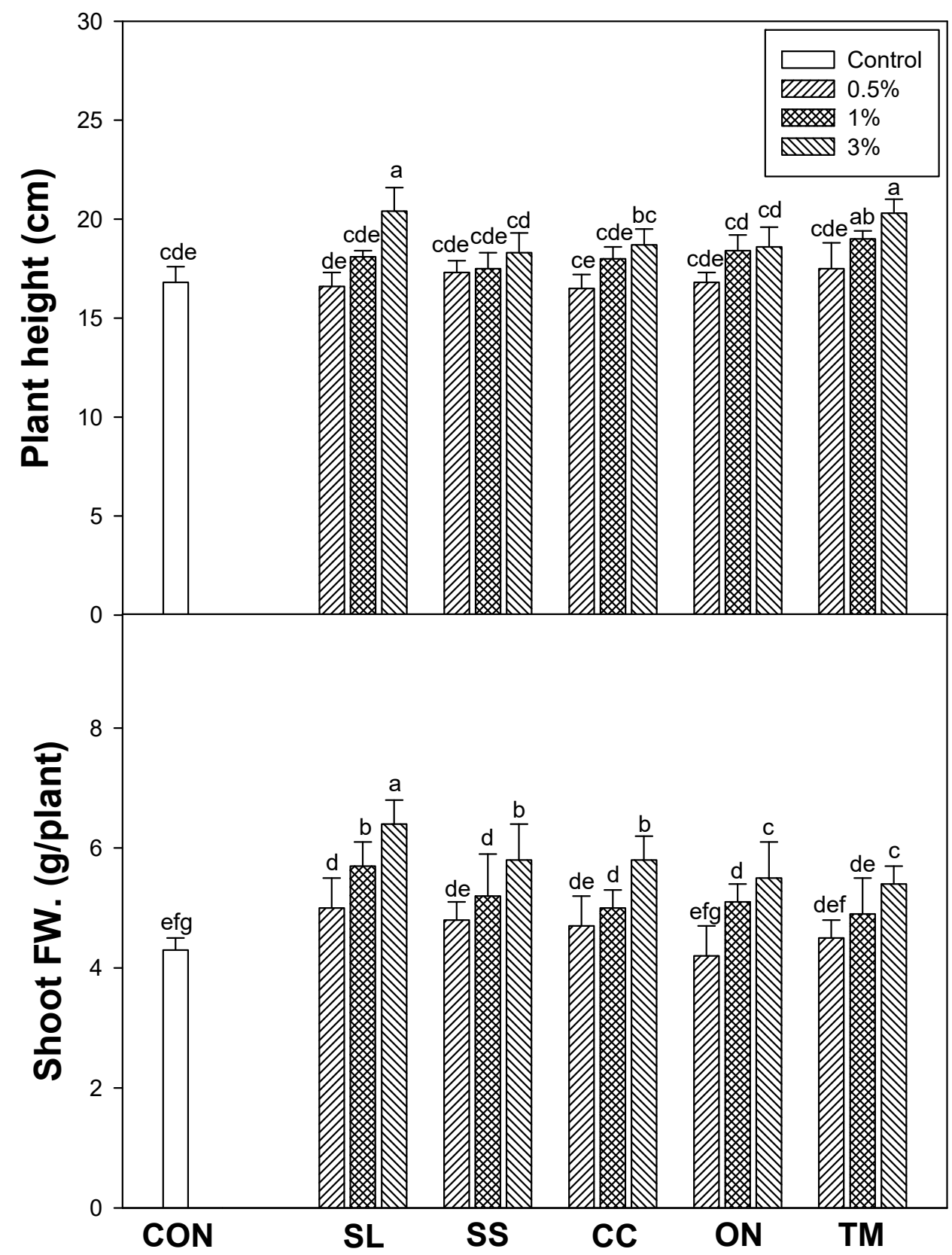

Figure 1. Effect of various plant extracts (SL, soybean leaf; SS, soybean stem; CC, Chinese chive, ON, onion; TM, tomato) on plant height and shoot fresh weight of Peucedanum japonicum. Means within bars followed by the same letters are not significantly different at the 5\% level according to Duncan's Multiple Range Test.

\subsection{Effect of Various Extracts on Growth of Peucedanum Japonicum}

Compared to the control, the plant height of Peucedanum japonicum was $21 \%$ greater when treated with the soybean leaf extract at a 3\% concentration (Figure 2). Moreover, the plant height was 18 and $21 \%$ greater in the plants treated with the tomato extracts at $1 \%$ and $3 \%$ concentrations, respectively. On the other hand, apart from the tomato and soybean leaf extracts, no other extract had a significant impact on the Peucedanum japonicum plant height. 


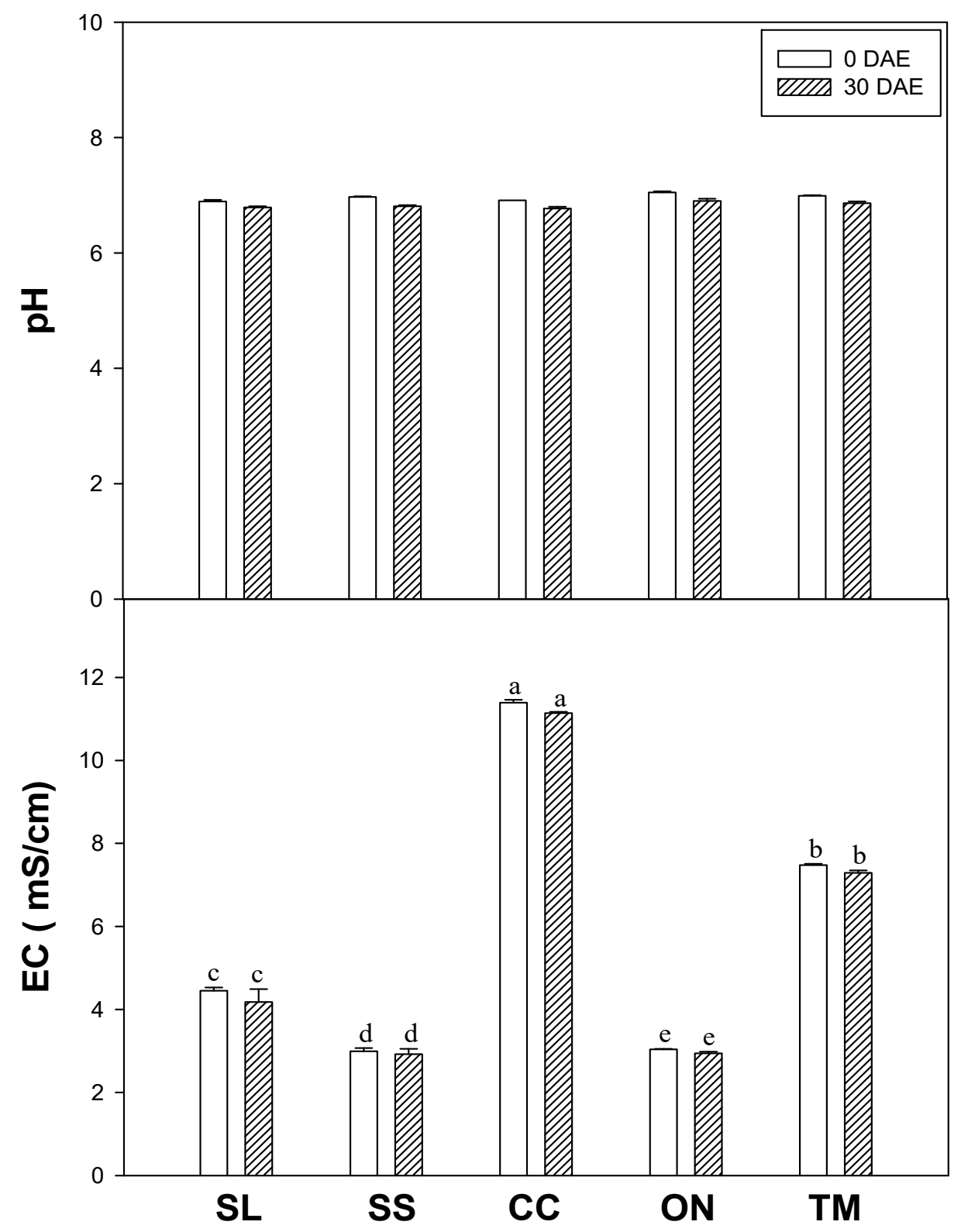

Figure 2. $\mathrm{pH}$ and EC values in various plant extracts (SL, soybean leaf; SS, soybean stem; CC, Chinese chive, $\mathrm{ON}$, onion; TM, tomato) at 0 and 30 days after extract (DAE). Means within bars followed by the same letters are not significantly different at the 5\% level according to Duncan's Multiple Range Test.

The fresh shoot weight of Peucedanum japonicum increased with increasing response to all the extracts used, particularly in those with higher concentrations. In particular, the fresh shoot weight was $16-49 \%$ greater than the control when the plants were treated with the soybean leaf extracts at $0.5 \%, 1 \%$, and $3 \%$. Among the extracts with low concentrations of $0.5 \%$, no significant difference in the fresh shoot weight was observed in the plants treated with the soybean stem, Chinese chive, onion, and tomato extracts. When extracts had higher concentrations of $1 \%$ and $3 \%$, however, the fresh shoot weight increased by $20-35 \%, 16-36 \%, 18-27 \%$, and $26 \%$ in response to the treatments with the soybean stem, Chinese chive, onion, and tomato extracts, respectively. The extract effectiveness of the fresh shoot-weight promotors was as follows: soybean leaves $>$ soybean stem $=$ Chinese chive $>$ onion $>$ tomato.

In a previous study, soybean leaves, soybean stems, and Chinese chive extracts also produced fresh shoot weight increases of $31-45 \%$ in lettuce compared to the control [9]. The growth promotion 
effects of the soybean leaves, soybean stems, and Chinese chive extracts were also observed when applied to endive and broccoli, but not to pak choi and kale. In another study [8], the red pepper fresh shoot weight increased $129-182 \%$ in the plants treated with the tomato water extract at 0.1 to $3 \%$ and increased $78-136 \%$ in the plants treated with the onion water extract at 0.1 to $3 \%$. The tomato fresh shoot weight increased $39-66 \%$ in the plants treated with the tomato water extract at 0.1 to $3 \%$ and increased $45-83 \%$ in the plants treated with the onion water extract at 0.1 to $3 \%$ concentrations. In a study using the same material but different extraction methods, the onion residue fermentation extracts increased the plant height, number of leaves, and yield compared to the control [22]. Overall, the plant extracts used in this study can be used for growth promotion in the organic cultivation of various crops.

\subsection{Photosynthetic Efficacy and Total Chlorophyll Reading (SPAD)}

Compared to the control, the photosynthetic efficiency of Peucedanum japonicum plants treated with soybean leaf, soybean stem, Chinese chive, onion, and tomato extracts did not vary significantly (Table 1). The chlorophyll content (SPAD values) was also similar in both the treated and control plants. In another study, there were no significant differences in the photosynthetic efficiency, chlorophyll, or carotenoid contents in the lettuce plants treated with Chinese chive, soybean leaf, and soybean stem water extracts and the untreated control [9]. This suggests that the increased growth in the extract-treated Peucedanum japonicum plants is not due to either the photosynthetic efficiency (quantum yield) or chlorophyll contents.

Table 1. Quantum yield (photosynthesis efficacy) and SPAD (Soil Plant Analysis Development) values (chlorophyll content) in Peucedanum japonicum at 7 and 14 days after treatment (DAT) of various plant extract.

\begin{tabular}{|c|c|c|c|c|c|}
\hline \multirow{2}{*}{ Extract } & \multirow{2}{*}{ Concentration $(\%)$} & \multicolumn{2}{|c|}{ Quantum Yield } & \multicolumn{2}{|c|}{ SPAD Value } \\
\hline & & 7 DAT & 14 DAT & 7 DAT & 14 DAT \\
\hline \multirow{5}{*}{ Soybean leaf } & Control & $0.838^{a b c}$ & $0.845^{b c}$ & $45.3^{a b c}$ & $44.4^{\mathrm{e}}$ \\
\hline & 0.5 & $0.844^{a b c}$ & $0.812^{a b}$ & $43.4^{\mathrm{ab}}$ & $45.6^{\mathrm{ab}}$ \\
\hline & 1 & $0.840^{a}$ & $0.837^{b c}$ & $47.2^{\mathrm{a}}$ & $45.9^{\mathrm{a}}$ \\
\hline & 3 & $0.848^{a b}$ & $0.844^{\mathrm{a}}$ & 42.9 bcde & $45.8^{\mathrm{abcd}}$ \\
\hline & 0.5 & $0.841^{a b c}$ & $0.843^{a b}$ & 45.9 cdef & $46.5^{\mathrm{abc}}$ \\
\hline \multirow[t]{2}{*}{ Soybean stem } & 1 & $0.841^{\mathrm{ab}}$ & $0.831^{b c}$ & 44.1 bcde & 43.9 abcde \\
\hline & 3 & $0.846^{\mathrm{ab}}$ & $0.829 \mathrm{bc}$ & $41.2^{\mathrm{f}}$ & 43.9 de \\
\hline & 0.5 & $0.841^{\mathrm{abc}}$ & $0.835^{b c}$ & 41.2 def & $44.2^{\text {cde }}$ \\
\hline \multirow[t]{3}{*}{ Chinese chive } & 1 & $0.666^{a b c}$ & $0.839^{a b}$ & $42.8^{\text {def }}$ & $44.0^{\mathrm{e}}$ \\
\hline & 3 & $0.844^{a b c}$ & $0.846^{a b}$ & $43.7^{\mathrm{abcd}}$ & $46.4^{\text {bcde }}$ \\
\hline & 0.5 & $0.844^{\mathrm{abc}}$ & $0.840^{\mathrm{ab}}$ & $45.0^{\mathrm{abc}}$ & $43.6^{\mathrm{e}}$ \\
\hline \multirow[t]{3}{*}{ Onion } & 1 & $0.842^{a b c}$ & $0.831^{\mathrm{c}}$ & $44.1^{\text {cdef }}$ & 45.0 bcde \\
\hline & 3 & $0.839 a b c$ & $0.841^{a b}$ & 40.1 ef & 44.4 abcde \\
\hline & 0.5 & $0.833^{b c}$ & $0.826^{b c}$ & $45.2^{a b c}$ & 43.9 bcde \\
\hline \multirow[t]{2}{*}{ Tomato } & 1 & $0.836^{\mathrm{c}}$ & $0.822^{\mathrm{d}}$ & $45.6^{\text {bcde }}$ & $46.1^{\text {bcde }}$ \\
\hline & 3 & $0.836^{b c}$ & $0.837^{b}$ & $45.6^{\text {bcde }}$ & $41.7^{\mathrm{e}}$ \\
\hline
\end{tabular}

Means within a column followed by the same letters are not significantly different at $5 \%$ level according to Duncan's Multiple Range Test.

Other studies, however, suggested that an increase in chlorophyll content could enhance the photosynthesis rates, which ultimately influence plant growth [23]. Bean (Phaseolus vulgaris) plants sprayed with Moringa oleifera leaf extract produced significantly larger amounts of photosynthetic pigments compared to the stressed plants [24]. Moreover, one of the characteristic responses to seaweed extract treatments is an increase in chlorophyll content in the treated plants, which has been observed in a wide range of crops, including grapevine and strawberry $[12,13,25]$. 
Therefore, the degree to which plant extract treatments may or may not increase the photosynthetic efficiency and chlorophyll contents can, according to the study, depending on which treated plants and extracts were used. Other mechanisms, such as higher mineral nutrient contents in the plant extracts themselves, and the nutrient uptake in the treated leaves could also be crucial to growth promotion.

\subsection{Levels of Mineral Nutrition in Extracts and Treated Leaves}

Of the extracts used in this study, the Chinese chive extracts contained the highest levels of macroelements, T-N (total nitrogen), P, K, Mg (Table 2). Soybean leaf extracts contained the highest levels of microelements, $\mathrm{Al}, \mathrm{Fe}, \mathrm{Ni}$, and $\mathrm{Zn}$, while the Chinese chive extracts contained the highest levels of microelements, $\mathrm{B}, \mathrm{Mn}, \mathrm{Cu}$, and Mo. Note that the levels of $\mathrm{Al}$ and $\mathrm{Fe}$ in the soybean leaf extract were 40-109 and 12-566 times higher than in the other extracts, respectively. In this study, however, extracts with the highest levels of mineral nutrients were not the most effective growth promotors of Peucedanum japonicum plants.

Previous studies also showed that higher levels of macro and microelements are not solely responsible for growth promotion $[9,19]$. This suggests that red pepper and tomato growth promotion may not be caused by high levels of one specific macro or microelement, but rather by some specific combination of various elements.

The nutrient levels in Peucedanum japonicum leaves were also measured after the plant extract treatments (Table 3). Plants absorb nutrients, either through roots or from the leaf surface. Plant extracts alter the physical, biochemical, and biological properties of the soil and may also affect the architecture of plant roots facilitating the efficient uptake of nutrients [26]. The total $\mathrm{N}$ in Peucedanum japonicum leaves increased significantly with increasing concentration $(0.5,1$, and $3 \%)$ when treated with the soybean leaf extract compared to the control. In addition, the total $\mathrm{N}$ in the Peucedanum japonicum leaves increased significantly when treated with the Chinese chive extract at $0.5 \%, 1 \%$, and $3 \%$ compared with control. The total $\mathrm{N}$ in Peucedanum japonicum leaves increased significantly when treated with the tomato extract at only 3\%. On the other hand, other extracts soybean stem and onion-treated Peucedanum japonicum leaves did not increase the $\mathrm{N}$ content significantly. The leaves from the $0.5 \%$, $1 \%$, and $3 \%$ all extracts-treated plants showed a significant increase in the P contents compared to the control. Generally, the Ca content in Peucedanum japonicum leaves increased significantly when treated with all the selected extracts. The Mg and Na contents also increased significantly in some extracts and some concentrations. The B content in the Peucedanum japonicum leaves increased significantly when treated with the soybean leaf extracts at $0.5 \%, 1 \%$, and $3 \%$; soybean stem extract at $1 \%$; and Chinese chive at 0.5 and $3 \%$ compared to the control. The onion and tomato extracts, however, did not increase the B levels significantly. The $\mathrm{Al}$ content in Peucedanum japonicum leaves increased significantly when treated with the soybean leaf extracts at $1 \%$ and $3 \%$; Chinese chive extracts at $0.5 \%, 1 \%$, and $3 \%$; and onion extract at $1 \%$ compared to the control. In particular, the $\mathrm{Al}$ content in the Peucedanum japonicum leaves treated with the Chinese chive extract at $0.5 \%$, and the onion extract at $1 \%$ was 5.1 and 2.4 times higher than the control, respectively. The $\mathrm{Mn}, \mathrm{Fe}$, and $\mathrm{Zn}$ contents in the Peucedanum japonicum leaves increased significantly when treated with all of the selected extracts. In particular, the Fe content in the Peucedanum japonicum leaves treated with the Chinese chive extract at $0.5 \%$ and onion extract at $0.5 \%$ were 2.3 and 11.1 times higher than the untreated control, respectively. A consistent increase in $\mathrm{Ni}$ content in Peucedanum japonicum leaves was not observed after the extract applications. The $\mathrm{Cu}$ and Mo contents in the Peucedanum japonicum leaves increased significantly when treated with the soybean leaf, soybean stem, Chinese chive, and onion extracts compared to the control. Overall, the rates of macroelements, such as $\mathrm{N}, \mathrm{P}, \mathrm{K}, \mathrm{Ca}$, and $\mathrm{Mg}$, were highest in the plants treated with soybean leaf and Chinese chive extracts. The contents of microelements, such as $\mathrm{Fe}, \mathrm{Mn}$, and $\mathrm{Zn}$, increased significantly in the plants treated with all the selected extracts. The increases in microelements in Peucedanum japonicum leaves after the extract treatments are in the following order: Chinese chive > soybean leaf $>$ onion $>$ soybean stem $>$ tomato. 
Table 2. Nutrition levels in various plant extracts.

\begin{tabular}{ccccccccccccccc}
\hline \multirow{2}{*}{ Extract } & \multicolumn{1}{c}{ Macroelements (\%) } & \multicolumn{4}{c}{ Microelements (mg/kg) } \\
\cline { 2 - 12 } & T-N & P & K & Ca & Mg & Na & B & Al & Mn & Fe & Ni & Cu & Zn & Mo \\
\hline Soybean leaf & $1.14^{\mathrm{c}}$ & $0.16^{\mathrm{b}}$ & $1.42^{\mathrm{d}}$ & $0.88^{\mathrm{a}}$ & $0.20^{\mathrm{b}}$ & $0.00^{\mathrm{c}}$ & $5.60^{\mathrm{b}}$ & 832.62 & $46.52^{\mathrm{b}}$ & $389.44^{\mathrm{a}}$ & $0.68^{\mathrm{a}}$ & $2.70^{\mathrm{c}}$ & $40.20^{\mathrm{a}}$ & $0.44^{\mathrm{b}}$ \\
Soybean stem & $0.06^{\mathrm{e}}$ & $0.00^{\mathrm{c}}$ & $1.20^{\mathrm{e}}$ & $0.14^{\mathrm{c}}$ & $0.10^{\mathrm{d}}$ & $0.06^{\mathrm{b}}$ & $1.82^{\mathrm{e}}$ & $7.66^{\mathrm{c}}$ & $2.48^{\mathrm{e}}$ & $6.94^{\mathrm{e}}$ & $0.18^{\mathrm{d}}$ & $1.92^{\mathrm{e}}$ & $2.46^{\mathrm{e}}$ & $0.04^{\mathrm{e}}$ \\
Chinese chive & $1.64^{\mathrm{a}}$ & $0.26^{\mathrm{a}}$ & $5.60^{\mathrm{a}}$ & $0.28^{\mathrm{b}}$ & $0.34^{\mathrm{a}}$ & $0.06^{\mathrm{b}}$ & $5.72^{\mathrm{a}}$ & $21.10^{\mathrm{b}}$ & $83.88^{\mathrm{a}}$ & $31.62^{\mathrm{b}}$ & $0.48^{\mathrm{b}}$ & $4.02^{\mathrm{a}}$ & $35.12^{\mathrm{b}}$ & $0.62^{\mathrm{a}}$ \\
Onion & $1.10^{\mathrm{d}}$ & $0.18^{\mathrm{b}}$ & $1.52^{\mathrm{c}}$ & $0.10^{\mathrm{d}}$ & $0.10^{\mathrm{d}}$ & $0.06^{\mathrm{b}}$ & $3.84^{\mathrm{c}}$ & $9.22^{\mathrm{c}}$ & $3.08^{\mathrm{d}}$ & $13.52^{\mathrm{d}}$ & $0.24^{\mathrm{c}}$ & $2.36^{\mathrm{d}}$ & $7.54^{\mathrm{d}}$ & $0.10^{\mathrm{d}}$ \\
Tomato & $1.26^{\mathrm{b}}$ & $0.22^{\mathrm{a}}$ & $3.90^{\mathrm{b}}$ & $0.08^{\mathrm{e}}$ & $0.16^{\mathrm{c}}$ & $0.12^{\mathrm{a}}$ & $3.56^{\mathrm{d}}$ & $7.62^{\mathrm{c}}$ & $5.82^{\mathrm{c}}$ & $22.34^{\mathrm{c}}$ & $0.16^{\mathrm{d}}$ & $2.88^{\mathrm{b}}$ & $14.50^{\mathrm{c}}$ & $0.22^{\mathrm{c}}$ \\
\hline
\end{tabular}

T-N, total nitrogen. Means within a column followed by the same letters are not significantly different at $5 \%$ level according to Duncan's Multiple Range Test.

Table 3. Nutrition levels in Peucedanum japonicum leaves treated plant extracts.

\begin{tabular}{|c|c|c|c|c|c|c|c|c|c|c|c|c|c|c|c|}
\hline \multirow{2}{*}{ Extract } & \multirow{2}{*}{$\mathrm{CO}(\%)$} & \multicolumn{6}{|c|}{ Macroelements (\%) } & \multicolumn{8}{|c|}{ Microelements (mg/kg) } \\
\hline & & T-N & $\mathbf{P}$ & $\mathbf{K}$ & $\mathrm{Ca}$ & Mg & $\mathbf{N a}$ & B & Al & Mn & $\mathrm{Fe}$ & $\mathrm{Ni}$ & $\mathrm{Cu}$ & Zn & Mo \\
\hline \multirow{4}{*}{$\begin{array}{l}\text { Soybean } \\
\text { leaf }\end{array}$} & Control & $2.65^{f}$ & $0.36^{\mathrm{i}}$ & $4.63^{\mathrm{f}}$ & $1.52 \mathrm{hi}$ & $0.40^{\mathrm{d}}$ & $1.60^{\mathrm{e}}$ & $23.13^{\mathrm{gh}}$ & 40.81 gh & $92.80^{1}$ & $61.80^{k}$ & $0.00^{\mathrm{e}}$ & $3.53^{f}$ & $18.05^{j}$ & 0.99 efg \\
\hline & 0.5 & $2.88^{\mathrm{c}}$ & $0.40^{\mathrm{h}}$ & $4.98^{c}$ & $1.68^{c}$ & 0.39 de & $1.69^{b}$ & $26.85^{\mathrm{a}}$ & $41.32^{\mathrm{g}}$ & $145.05^{\mathrm{a}}$ & $69.12^{\mathrm{h}}$ & $0.00^{\mathrm{e}}$ & $4.17^{b}$ & $22.12^{c}$ & $1.10^{\text {cdef }}$ \\
\hline & 1 & $3.01^{\mathrm{b}}$ & $0.43 \mathrm{~g}$ & $5.23^{\mathrm{a}}$ & $1.64^{\mathrm{d}}$ & $0.38^{\mathrm{fg}}$ & 1.59 ef & $26.87^{a}$ & $51.67^{\mathrm{d}}$ & $115.29^{\mathrm{f}}$ & $84.20^{\mathrm{d}}$ & $0.24^{b}$ & $3.75^{\mathrm{d}}$ & $23.94^{\mathrm{a}}$ & $1.16^{\text {bcde }}$ \\
\hline & 3 & $3.16^{\mathrm{a}}$ & 0.49 ef & $4.94^{\mathrm{d}}$ & $1.72^{\mathrm{b}}$ & $0.44^{\mathrm{b}}$ & $1.36^{1}$ & $25.09 \mathrm{bc}$ & $45.10^{\mathrm{e}}$ & $137.88^{\mathrm{c}}$ & $74.88^{f}$ & $0.00^{\mathrm{e}}$ & $4.18^{\mathrm{b}}$ & $21.99^{c}$ & $1.19^{b c}$ \\
\hline \multirow{3}{*}{$\begin{array}{l}\text { Soybean } \\
\text { stem }\end{array}$} & 0.5 & $2.44^{\mathrm{h}}$ & $0.33^{j}$ & $4.81^{\mathrm{e}}$ & $1.52^{\mathrm{ij}}$ & $0.35^{\mathrm{j}}$ & $1.49^{\mathrm{i}}$ & $20.99^{k}$ & $34.58^{\mathrm{k}}$ & $76.81^{\circ}$ & $64.80^{j}$ & $0.00^{\mathrm{e}}$ & $3.63^{\mathrm{e}}$ & $18.45^{\mathrm{i}}$ & $0.88^{g}$ \\
\hline & 1 & 2.69 ef & $0.32^{j}$ & $4.60^{g}$ & $1.51 \mathrm{ij}$ & $0.36^{\text {hi }}$ & $1.34^{\mathrm{m}}$ & $24.10^{\mathrm{e}}$ & $33.89^{1}$ & $93.75^{k}$ & $64.50^{j}$ & $0.00^{\mathrm{e}}$ & $3.28^{\mathrm{i}}$ & $17.67^{\mathrm{k}}$ & $1.36^{\mathrm{a}}$ \\
\hline & 3 & $2.53 \mathrm{~g}$ & 0.50 de & $4.60^{g}$ & $1.62^{\mathrm{e}}$ & $0.41^{c}$ & $1.55^{\mathrm{gh}}$ & $23.02^{h}$ & $38.89^{i}$ & $112.92^{g}$ & $68.84^{h}$ & $0.00^{\mathrm{e}}$ & $3.48 \mathrm{fg}$ & $20.68^{f}$ & $1.04^{\text {cdefg }}$ \\
\hline \multirow{3}{*}{$\begin{array}{l}\text { Chinese } \\
\text { chive }\end{array}$} & 0.5 & $2.74 \mathrm{de}$ & $0.64^{\mathrm{a}}$ & $5.01^{b}$ & $1.79^{\mathrm{a}}$ & $0.44^{b}$ & $1.64^{\mathrm{d}}$ & $25.19^{b}$ & $207.69^{a}$ & $143.65^{b}$ & $139.04^{b}$ & $0.00^{\mathrm{e}}$ & $3.82^{c}$ & $21.57^{\mathrm{d}}$ & $1.08^{\text {cdef }}$ \\
\hline & 1 & $2.75^{\mathrm{d}}$ & $0.58^{\mathrm{c}}$ & $4.28^{\mathrm{j}}$ & $1.57 \mathrm{~g}$ & $0.38^{\mathrm{fg}}$ & $1.56^{\mathrm{g}}$ & $23.26^{\mathrm{g}}$ & $42.52^{\mathrm{f}}$ & $124.08^{\mathrm{e}}$ & $73.51 \mathrm{~g}$ & $0.17^{\mathrm{c}}$ & $3.45 \mathrm{~g}$ & $21.11^{\mathrm{e}}$ & 0.99 efg \\
\hline & 3 & $2.87^{\mathrm{c}}$ & $0.61^{b}$ & $4.61^{\mathrm{g}}$ & $1.59^{\mathrm{f}}$ & 0.39 ef & $1.81^{\mathrm{a}}$ & $24.97^{c}$ & $72.77^{c}$ & $137.25^{\mathrm{d}}$ & $82.91^{\mathrm{e}}$ & $0.00^{\mathrm{e}}$ & $4.29^{a}$ & $21.72^{\mathrm{d}}$ & $1.31^{\mathrm{ab}}$ \\
\hline \multirow{3}{*}{ Onion } & 0.5 & $2.33^{i}$ & $0.32^{\mathrm{j}}$ & $4.08^{1}$ & $1.51^{\mathrm{ij}}$ & $0.36^{\mathrm{h}}$ & $1.58^{f}$ & $22.81^{\mathrm{i}}$ & $40.48^{\mathrm{h}}$ & $88.90^{\mathrm{m}}$ & $680.25^{a}$ & $0.00^{\mathrm{e}}$ & $3.54^{f}$ & $19.07^{\mathrm{h}}$ & $0.93 \mathrm{fg}$ \\
\hline & 1 & $2.69^{f}$ & $0.44^{\mathrm{g}}$ & $4.06^{\mathrm{m}}$ & $1.66^{\mathrm{c}}$ & $0.37^{g}$ & $1.54^{\mathrm{h}}$ & $22.42^{j}$ & $96.48^{b}$ & $137.75^{c}$ & $88.18^{c}$ & $0.33^{a}$ & $3.74^{\mathrm{d}}$ & $22.95^{b}$ & $1.18^{b c d}$ \\
\hline & 3 & $2.66^{\mathrm{f}}$ & $0.52^{d}$ & $4.57^{\mathrm{h}}$ & $1.54^{\mathrm{h}}$ & $0.33^{k}$ & $1.66^{\mathrm{c}}$ & $24.46^{\mathrm{d}}$ & $38.90^{\mathrm{i}}$ & $95.20^{\mathrm{j}}$ & $67.58^{\mathrm{i}}$ & $0.06^{\mathrm{d}}$ & $3.38^{\mathrm{h}}$ & $19.38 \mathrm{~g}$ & $0.96^{\mathrm{fg}}$ \\
\hline \multirow{3}{*}{ Tomato } & 0.5 & $2.43^{h}$ & $0.44^{\mathrm{g}}$ & $4.24^{\mathrm{k}}$ & $1.58^{\mathrm{fg}}$ & $0.34^{\mathrm{k}}$ & $1.40^{\mathrm{k}}$ & $23.63^{f}$ & $27.88^{n}$ & $88.00^{n}$ & $52.21^{\mathrm{m}}$ & $0.00^{\mathrm{e}}$ & $3.13^{j}$ & $19.48^{\mathrm{g}}$ & 1.01 defg \\
\hline & 1 & $2.23^{j}$ & $0.47^{\mathrm{f}}$ & $3.81^{n}$ & $1.50^{\mathrm{j}}$ & $0.35^{\mathrm{ij}}$ & $1.67^{b c}$ & $23.08^{h}$ & $32.30^{\mathrm{m}}$ & $103.76^{\mathrm{i}}$ & $58.12^{1}$ & $0.00^{\mathrm{e}}$ & $3.08^{j}$ & $15.73^{1}$ & $0.96^{\mathrm{fg}}$ \\
\hline & 3 & $2.86^{\mathrm{C}}$ & $0.66^{\mathrm{a}}$ & $4.47^{\mathrm{i}}$ & $1.48^{\mathrm{k}}$ & $0.47^{\mathrm{a}}$ & $1.46^{\mathrm{j}}$ & $18.71^{1}$ & $36.15^{j}$ & $108.23^{h}$ & $64.36^{j}$ & $0.00^{\mathrm{e}}$ & $3.54^{f}$ & $20.68^{f}$ & $1.07^{\mathrm{cdef}}$ \\
\hline
\end{tabular}

$\mathrm{CO}$, concentration; T-N, total nitrogen. Means within a column followed by the same letters are not significantly different at 5\% level according to Duncan's Multiple Range Test. 
The findings of this study are consistent with similar studies. In a plant metabolism study, the applications of seaweed extract to grapevines increased the leaf accumulation of $\mathrm{N}, \mathrm{P}, \mathrm{K}, \mathrm{Mg}$, and Zn [11]. Rathore et al. [27] also showed the accumulation of N, P, K, and S in the soybean seeds treated with the seaweed extracts. In a similar study, Crouch et al. [28] indicated that using seaweed concentrate led to significant increases in the $\mathrm{K}, \mathrm{Mg}$, and Ca concentrations in the leaves of lettuce plants that had received an adequate supply of nutrients but had little effect on the nutrients in stressed plants. Tomato fruit from plants treated with $0.2 \%$ and $0.5 \%$ concentrations of Ascophyllum nodosum exhibited significant increases in the N, P, K, Fe, and Zn contents [29].

In general, treated plants had higher mineral contents than untreated plants. Enhanced plant growth following the application of a plant extract could be due to bio-fertilization. The increased mineral content in the treated leaves can be explained, at least in part, by the increase in root biomass, which typically increases the foraging capacity of roots and uptake of soil minerals. Although the applications of plant extracts increased the nutrition level in the treated Peucedanum japonicum leaves, extracts with the highest levels of growth-promoting characteristics did not necessarily produce plant leaves with the highest mineral nutrient contents. This means that growth promotion may not be caused by the high levels of one specific macro or microelement, but rather by some specific combination of various elements.

\subsection{Phenol and Flavonoid Contents and DPPH Radical Scavenging Activity}

The soybean leaf extracts contain higher levels of flavonoids, such as salicylic, 4-hydroxybenzoic, vanillic, 4-hydrooxycinnamic, ferulic, caffeic, gentisic, and quercetin [30]. Chinese chives also contain higher contents of $\beta$-carotene, vitamin $C$, sulfur-containing compounds, and many kinds of flavonoids [31]. Onion and tomato also exhibit various bioactive properties and substances $[9,20]$. The application of seaweed extract caused an increase in the concentration of phenolic and flavonoid compounds in cabbage, potato, and onion [32,33]. Therefore, this study measured the phenol and flavonoid contents and DPPH radical scavenging activity not just in the extracts themselves, but also in Peucedanum japonicum leaves that had been treated with extracts (Table 4).

Table 4. Total phenol, total flavonoid contents and DPPH radical scavenging activity in Peucedanum japonicum leaves treated with plant extracts.

\begin{tabular}{|c|c|c|c|c|}
\hline Extract & $\mathrm{CO}(\%)$ & Phenol (mg/g) & Flavonoid (mg/g) & DPPH (\%) \\
\hline \multirow{4}{*}{ Soybean leaf } & Control & $0.91^{\mathrm{f}}$ & $0.088^{\text {ef }}$ & $10.12^{d}$ \\
\hline & 0.5 & $1.01 \mathrm{dfe}$ & $0.108^{b c d}$ & $27.35^{b c}$ \\
\hline & 1 & $0.94^{\mathrm{f}}$ & $0.120^{a b}$ & $32.37^{a b c}$ \\
\hline & 3 & $0.96^{\mathrm{ef}}$ & $0.118^{a b c}$ & $30.46^{\mathrm{bc}}$ \\
\hline \multirow{3}{*}{ Soybean stem } & 0.5 & $0.91^{\mathrm{f}}$ & $0.126^{a}$ & $27.31 \mathrm{bc}$ \\
\hline & 1 & $0.90^{f}$ & 0.090 def & $33.06^{a b c}$ \\
\hline & 3 & $1.36^{\mathrm{b}}$ & 0.094 def & $25.11^{c}$ \\
\hline \multirow{3}{*}{ Chinese chive } & 0.5 & 1.20 bcde & 0.100 cdef & $29.82^{b c}$ \\
\hline & 1 & $1.65^{\mathrm{a}}$ & $0.105^{\text {bcde }}$ & $32.10^{a b c}$ \\
\hline & 3 & $1.27^{b c}$ & $0.084^{\mathrm{f}}$ & $38.95^{a b c}$ \\
\hline \multirow{3}{*}{ Onion } & 0.5 & $1.60^{\mathrm{a}}$ & $0.106^{\text {bcde }}$ & $41.69^{a b}$ \\
\hline & 1 & $0.92^{f}$ & 0.097 def & $45.25^{\mathrm{a}}$ \\
\hline & 3 & $1.15^{\text {bcdef }}$ & 0.099 def & $28.68^{b c}$ \\
\hline \multirow{3}{*}{ Tomato } & 0.5 & $0.98^{\text {ef }}$ & $0.106^{\text {bcde }}$ & $37.44^{\mathrm{abc}}$ \\
\hline & 1 & $1.03^{\text {cdef }}$ & $0.105^{\text {bcde }}$ & $27.40^{b c}$ \\
\hline & 3 & $1.25^{b c d}$ & $0.100^{\text {cdef }}$ & $29.50^{b c}$ \\
\hline
\end{tabular}

$\mathrm{CO}$, concentration. Means within a column followed by the same letters are not significantly different at $5 \%$ level according to Duncan's Multiple Range Test. 
The total phenol contents in Peucedanum japonicum leaves increased significantly when treated with the soybean stem extracts at $3 \%$, Chinese chive extracts at 0.5 to $3 \%$, onion extract at $0.5 \%$, or tomato extract at $3 \%$. In particular, the total phenol content in the Peucedanum japonicum leaves treated with the Chinese chive extract at $0.5-3 \%$ increased by $32-81 \%$ compared to the control. On the other hand, the soybean leaf extract-treated Peucedanum japonicum leaves did not have significantly different total phenol contents.

The total flavonoid contents in the Peucedanum japonicum leaves after being treated with the soybean leaf extracts at $0.5-3 \%$ increased by $23-36 \%$ compared to the control. Nevertheless, the total flavonoid contents in the Peucedanum japonicum leaves were similar when treated with the soybean stem, Chinese chive, onion, and tomato extracts. In another study, the flavonoid contents increased in the Tithonia diversifolia-treated tomato plants [34]. Similarly, neem (Azadirachta indica) extracts applied to tomatoes have been observed to increase the abundance of several flavonoids through the jasmonate pathway [35].

The DPPH radical scavenging activity in Peucedanum japonicum leaves increased significantly when treated with all the selected extracts at $0.5-3 \%$ compared to the control. In particular, the highest DPPH radical scavenging activity $(42-45 \%)$ in the Peucedanum japonicum leaves was observed in the plants treated with the onion extract at $0.5 \%$ and $1 \%$. Moreover, the DPPH radical scavenging activity in the Peucedanum japonicum leaves was 39\% in the plants treated with the Chinese chive extracts at 3\% and $37 \%$ in the plants treated with the tomato extracts at $0.5 \%$.

Previous studies have shown that the treatments of spinach with commercial A. nodosum extracts improve not only the storage quality but also the flavonoid synthesis and nutritional quality of the spinach leaf $[17,25]$. In a similar study, $A$. nodosum extracts improved the productivity, quality, and nutrient status of olives [36]. Consistent with these studies, the selected plant extracts also improved growth promotion, mineral contents, total phenol, total flavonoid contents, and DPPH radical scavenging activity.

\section{Conclusions}

The fresh shoot weight of Peucedanum japonicum increased in response to all the extracts used. In particular, the fresh shoot weight was $16-49 \%$ greater than the control when the plants were treated with soybean leaf extracts at $0.5 \%, 1 \%$, and $3 \%$. The extract effectiveness from the most effective to least effective fresh shoot weight promotors is as follows: soybean leaves $>$ soybean stem $=$ Chinese chive $>$ onion $>$ tomato. The Chinese chive extracts contained the highest levels of T-N, P, K, and Mg. The soybean leaf extracts contained the highest levels of $\mathrm{Al}, \mathrm{Fe}, \mathrm{Ni}$, and $\mathrm{Zn}$, whereas the Chinese chive extracts contained the highest levels of $\mathrm{B}, \mathrm{Mn}, \mathrm{Cu}$, and $\mathrm{Mo}$. The contents of macroelements, such as $\mathrm{N}, \mathrm{P}, \mathrm{K}, \mathrm{Ca}$, and $\mathrm{Mg}$, and microelements, such as $\mathrm{Fe}, \mathrm{Mn}$, and $\mathrm{Zn}$, in Peucedanum japonicum leaves increased significantly when treated with all the extracts tested.

In this study, however, the extracts with the highest levels of mineral nutrients were not the most effective growth promotors of Peucedanum japonicum plants. The total phenol contents in the Peucedanum japonicum leaves increased significantly when treated with the soybean stem extract at $3 \%$, Chinese chive extract at $0.5-3 \%$, onion extract at $0.5 \%$, or tomato extract at $3 \%$. The total flavonoid contents in the Peucedanum japonicum leaves treated with the soybean leaf extracts at concentrations ranging from 0.5 to $3 \%$ increased by $23-36 \%$ compared to the control. Overall, the plant extracts tested in this study showed improved growth promotion, mineral contents, total phenol, total flavonoid contents, and DPPH radical scavenging activity.

Author Contributions: Data curation, H.H.P. and S.J.J.; writing-original draft preparation, S.J.J. and Y.I.K; writing-review and editing, Y.I.K. All authors have read and agreed to the published version of the manuscript.

Funding: This work was carried out with the support of "Cooperative Research Program for Agriculture Science \& Technology Development (Project No. PJ01338805)" Rural Development Administration, Republic of Korea.

Aknowledgements: The authors acknowledge the help of Min Hee Park, Hyo Jin Lee, and Ok Gi Lee in crop cultivation. 
Conflicts of Interest: The authors declare no conflict of interest.

\section{References}

1. Chae, J.C.; Gang, B.H.; Park, S.J.; Kim, S.H. Samgo Cultivation Principles; Hyangmunsa: Seoul, Korea, 2008; p. 434. (In Korean)

2. Tworkoski, T. Herbicide effects of essential oils. Weed Sci. 2002, 50, 425-431. [CrossRef]

3. An, N.H.; Kim, Y.K.; Lee, Y.; Jee, H.J.; Park, J.H.; Hong, S.J.; Han, E.J. Changes in chemical properties and microbial population of farm-made organic liquid fertilizer during fermenting process. Korean J. Org. Agric. 2011, 19, 417-425.

4. Jung, H.-K.; Jung, W.-S.; Ahn, B.-K.; Kang, B.-M.; Yeo, J.-H.; Cha, S.-W.; Park, C.-G.; Cho, J.-H.; Cho, H.W. Peucedanum japonicum Thunberg Leaf Alleviates the Symptoms of Dextran Sulfate Sodium Induced Ulcerative Colitis in Mice. Korean J. Plant Resour. 2014, 27, 421-428. [CrossRef]

5. Jang, S.J.; Kuk, Y.I. Crop growth promotion and mineral nutrient levels in various extracts of onion (Allium cepa) and tomato (Lycopersicon esculentum). Res. Crops 2020, 21, 315-326.

6. Hartz, T.; Smith, R.; Gaskell, M. Nitrogen Availability from Liquid Organic Fertilizers. HortTechnology 2010, 20, 169-172. [CrossRef]

7. Kuk, Y.I.; Yun, Y.B.; Jang, S.J.; Jeong, J.Y.; Kim, D.S.; Kim, S.S. Evaluation of tomato growth-promoting effect and mineral nutrient of farm-made liquid fertilizers. Korean J. Org. Agric. 2019, 27, 205-224.

8. Jang, S.J.; Kuk, Y.I. Evaluation on the performance of red pepper (Capsicum annuum) and tomato (Lycopersicon esculentum) under various fermented liquid fertilizers. Res. Crops 2020, 21, 306-314.

9. Jang, S.J.; Kuk, Y.I. Growth promotion effects of plant extracts on various leafy vegetable crops. Hortic. Sci. Technol. 2019, 37, 322-336.

10. Khan, W.; Rayirath, U.P.; Subramanian, S.; Jithesh, M.N.; Rayorath, P.; Hodges, D.M.; Critchley, A.T.; Craigie, J.S.; Norrie, J.; Prithiviraj, B. Seaweed Extracts as Biostimulants of Plant Growth and Development. J. Plant Growth Regul. 2009, 28, 386-399. [CrossRef]

11. Mancuso, S.; Azzarello, E.; Mugnai, S.; Briand, X. Marine bioactive substance (IPA extract) improve foliar ion uptake and water stress tolerance in potted Vitis vinifera plants. Adv. Hortic. Sci. 2006, 20, 156-161.

12. Spinelli, F.; Fiori, G.; Noferini, M.; Sprocatti, M.; Costa, G. Perspectives on the use of a seaweed extract to moderate the negative effects of alternate bearingin apple trees. J. Hortic. Sci. Biotechnol. 2009, 84, 131-137. [CrossRef]

13. Jannin, L.; Arkoun, M.; Etienne, P.; Laîné, P.; Goux, D.; Garnica, M.; Fuentes, M.; Francisco, S.S.; Baigorri, R.; Cruz, F.; et al. Brassica napus Growth is Promoted by Ascophyllum nodosum (L.) Le Jol. Seaweed Extract: Microarray Analysis and Physiological Characterization of N, C, and S Metabolisms. J. Plant Growth Regul. 2012, 32, 31-52. [CrossRef]

14. Liu, J.; Osbourn, A.; Ma, P. MYB Transcription Factors as Regulators of Phenylpropanoid Metabolism in Plants. Mol. Plant 2015, 8, 689-708. [CrossRef] [PubMed]

15. Dixon, R.A.; Paiva, N.L. Stress-induced phenylpropanoid metabolism. Plant Cell 1995, 7, $1085-1097$. [CrossRef] [PubMed]

16. Tsormpatsidis, E.; Henbest, R.; Battey, N.; Hadley, P. The influence of ultraviolet radiation on growth, photosynthesis and phenolic levels of green and red lettuce: potential for exploiting effects of ultraviolet radiation in a production system. Ann. Appl. Biol. 2010, 156, 357-366. [CrossRef]

17. Fan, D.; Hodges, D.M.; Zhang, J.; Kirby, C.; Ji, X.; Locke, S.J.; Critchley, A.T.; Prithiviraj, B. Commercial extract of the brown seaweed Ascophyllum nodosum enhances phenolic antioxidant content of spinach (Spinacia oleracea L.) which protects Caenorhabditis elegans against oxidative and thermal stress. Food Chem. 2011, 124, 195-202. [CrossRef]

18. Rural Development Administration (RDA). Methods of Soil and Plant Analysis; Sammi Press: Seoul, Korea, 2000; pp. 1-202.

19. Jang, S.J.; Kim, Y.J.; Kuk, Y.I. Effects of Allium species plant extracts and their active ingredients on inhibition of plant growth. Res. Crops 2019, 20, 576-584.

20. Jang, S.J. Control of Diseases, Insects, and Weeds and Growth Promotion of Crops by Useful Plant Extracts. Ph.D. Thesis, Sunchon National University, Suncheon, Korea, December 2017; p. 205. 
21. Statistical Analysis System (SAS). SAS/STAT User's Guide; Electronic Version; Statistical Analysis System Institute: Cary, NC, USA, 2000; Version 7.

22. Kim, T.W.; Jeon, B.G.; Lee, S.H. Effect of a mixture of extracts from residues of onion left after onion harvesting and purslane (Portulaca oleracea) on productivity and quality characteristics of organic onions. J. Life Sci. 2017, 27, 1430-1436.

23. Pereira, L.D.M.; Pereira, E.D.M.; Revolti, L.T.M.; Zingaretti, S.M.; Môro, G.V. Seed quality, chlorophyll content index and leaf nitrogen levels in maize inoculated with Azospirillum brasilense. Rev. Ciênc. Agron. 2015, 46, 630-637. [CrossRef]

24. Latif, H.; Mohamed, H. Exogenous applications of moringa leaf extract effect on retrotransposon, ultrastructural and biochemical contents of common bean plants under environmental stresses. S. Afr. J. Bot. 2016, 106, 221-231. [CrossRef]

25. Fan, D.; Hodges, D.M.; Critchley, A.T.; Prithiviraj, B. A Commercial Extract of Brown Macroalga (Ascophyllum nodosum) Affects Yield and the Nutritional Quality of SpinachIn Vitro. Commun. Soil Sci. Plant Anal. 2013, 44, 1873-1884. [CrossRef]

26. Battacharyya, D.; Babgohari, M.Z.; Rathor, P.; Prithiviraj, B. Seaweed extracts as biostimulants in horticulture. Sci. Hortic. 2015, 196, 39-48. [CrossRef]

27. Rathore, S.; Chaudhary, D.R.; Boricha, G.; Ghosh, A.; Bhatt, B.; Zodape, S.; Patolia, J. Effect of seaweed extract on the growth, yield and nutrient uptake of soybean (Glycine max) under rainfed conditions. S. Afr. J. Bot. 2009, 75, 351-355. [CrossRef]

28. Crouch, I.J.; Beckett, R.P.; Van Staden, J. Effect of seaweed concentrate on the growth and mineral nutrition of nutrient-stressed lettuce. Environ. Biol. Fishes 1990, 2, 269-272. [CrossRef]

29. Ali, N.; Farrell, A.; Ramsubhag, A.; Jayaraman, J. The effect of Ascophyllum nodosum extract on the growth, yield and fruit quality of tomato grown under tropical conditions. Environ. Biol. Fishes 2015, 28, 1353-1362. [CrossRef]

30. Porter, P.; Banwart, W.; Hassett, J. Phenolic acids and flavonoids in soybean root and leaf extracts. Environ. Exp. Bot. 1986, 26, 65-73. [CrossRef]

31. Moon, G.S.; Ryu, B.M.; Lee, M.J. Components and antioxidant activities of Buchu (Chinese chives) harvested at different times. Korean J. Food Sci. Technol. 2003, 35, 493-498.

32. Lola-Luz, T.; Hennequart, F.; Gaffney, M. Enhancement of phenolic and flavonoid compounds in cabbage (Brassica oleraceae) following application of commercial seaweed extracts of the brown seaweed, (Ascophyllum nodosum). Agric. Food Sci. 2013, 22, 288-295. [CrossRef]

33. Lola-Luz, T.; Hennequart, F.; Gaffney, M. Effect on health promoting phytochemicals following seaweed application, in potato and onion crops grown under a low input agricultural system. Sci. Hortic. 2014, 170, 224-227. [CrossRef]

34. Mkindi, A.G.; Tembo, Y.L.B.; Mbega, E.R.; Kendal-Smith, A.; Farrell, I.W.; Ndakidemi, P.A.; Stevenson, P.C.; Belmain, S.R. Extracts of Common Pesticidal Plants Increase Plant Growth and Yield in Common Bean Plants. Plants 2020, 9, 149. [CrossRef]

35. Pretali, L.; Bernardo, L.; Butterfield, T.S.; Trevisan, M.; Lucini, L. Botanical and biological pesticides elicit a similar Induced Systemic Response in tomato (Solanum lycopersicum) secondary metabolism. Phytochemistry 2016, 130, 56-63. [CrossRef] [PubMed]

36. Chouliaras, V.; Tasioula, M.; Chatzissavvidis, C.; Therios, I.; Tsabolatidou, E. The effects of a seaweed extract in addition to nitrogen and boron fertilization on productivity, fruit maturation, leaf nutritional status and oil quality of the olive (Olea europaea L.) cultivar Koroneiki. J. Sci. Food Agric. 2009, 89, 984-988. [CrossRef]

(C) 2020 by the authors. Licensee MDPI, Basel, Switzerland. This article is an open access article distributed under the terms and conditions of the Creative Commons Attribution (CC BY) license (http://creativecommons.org/licenses/by/4.0/). 